\title{
The Involvement of ATP-Sensitive Potassium Channels in the Nebivolol-Induced Relaxation of Endothelium- Intact Aorta Isolated from Rats
}

\author{
Hande Özge Altunkaynak-Camca ${ }^{1}$ \\ ${ }^{1}$ Department of Pharmacology, Gülhane Faculty of Pharmacy, University of Health Sciences Turkey, Ankara, Turkey \\ Received: 27 March 2020, Accepted: 27 May 2020, Published online: 31 August 2020 \\ (C) Ordu University Institute of Health Sciences, Turkey, 2020
}

\begin{abstract}
Objective: Nebivolol is a highly selective beta-1 adrenergic receptor blocker with additional vasorelaxant properties. The vasorelaxant effect of nebivolol has been mainly attributed to endothelium-dependent mechanisms including beta-adrenergic receptors. However, the involvement of ATP-sensitive potassium $\left(\mathrm{K}_{\mathrm{ATP}}\right)$ channels, another potential mechanism for vasorelaxant effect, in the vasorelaxant response to nebivolol remains unclear. Therefore, this study was aimed to investigate the role of $K_{\text {ATP }}$ channels in the nebivolol-induced vasorelaxation in the isolated rat aorta

Methods: The rat thoracic aortic rings isolated from Sprague-Dawley rats were mounted in organ bath chambers containing Krebs-Henseleit solution at $37{ }^{\circ} \mathrm{C}$ continuously bubbled with $95 \% \mathrm{O} 2$ and $5 \% \mathrm{CO} 2$. After an equilibration period, the presence of endothelium was confirmed by the response (more than 50\%) to acetylcholine $(10 \mu \mathrm{M})$ in aortic rings precontracted with phenylephrine $(1 \mu \mathrm{M})$. After washout, in control group, the endothelium-intact aortic rings were contracted by potassium chloride $(30 \mathrm{mM})$ before the cumulative addition of nebivolol $(0.0001-100 \mu \mathrm{M})$. In some experiments, the relaxant response to nebivolol $(0.0001-100 \mu \mathrm{M})$ was also obtained in the presence of glibenclamide $\left(\mathrm{K}_{\mathrm{ATP}}\right.$ channel blocker, $\left.10 \mu \mathrm{M}\right)$ or $\mathrm{N} \omega$ Nitro-L-arginine methyl ester (L-NAME: eNOS inhibitor, $100 \mu \mathrm{M}$ ) in the endothelium-intact aortic rings precontracted with potassium chloride $(30 \mathrm{mM})$. Data were presented as means \pm SEM. Multiple comparisons of groups were performed by using ANOVA followed by post-hoc Bonferroni test.

Results: Nebivolol elicited a concentration dependent vasorelaxant effect in the endothelium-intact aortic rings. Relaxant response to nebivolol was significantly inhibited by the presence of glibenclamide or LNAME $(\mathrm{p}<0.05)$. Although $\mathrm{E}_{\max }$ values were not found significantly different among groups, $\mathrm{pD}_{2}$ values of nebivolol were reduced in the endothelium-intact aortic rings incubated with glibenclamide or L-NAME.

Conclusion: These results demonstrate for the first time the involvement of $K_{\text {ATP }}$ channels in the nebivololinduced vasorelaxation in the endothelium-intact aorta precontracted with potassium chloride.
\end{abstract}

Key words: Nebivolol, vasorelaxation, ATP-sensitive potassium channels, nitric oxide, rat aorta.

Suggested Citation: Altunkaynak-Camca HO. The Involvement of ATP-Sensitive Potassium Channels in the Nebivolol-Induced Relaxation of Endothelium-Intact Aorta Isolated from Rats. Middle Black Sea Journal of Health Science, 2020; 6(2):201-206.

Address for correspondence/reprints:

Hande Özge Altunkaynak-Camca

Telephone number: +90(312) 3046073
ORCID-ID 0000-0002-4547-7756

E-mail: handeozgealtunkaynak.camca@sbu.edu.tr

DOI: $\quad 10.19127 / \mathrm{mbsjohs.708294}$ 


\section{Introduction}

Nebivolol is a third-generation, cardioselective beta $(\beta)$-blocker with additional antioxidant and vasorelaxant properties. The latter effect of nebivolol is closely associated with nitric oxide (NO) production by endothelium-dependent mechanisms (Cicero et al., 2018; Olawi et al., 2019).

The involvement of the endothelium in the vascular tone has been widely documented (Félétou $\mathrm{M}$ and Vanhoutte, 2006). In this regard, there is increasing evidence showing that endothelial beta- 2 $(\beta 2)$ - and/or $\beta 3$-ARs are primarily responsible for the vasorelaxant response to nebivolol (Broeders et al., 2000; de Groot et al., 2003). These receptors belong to the G-protein coupled receptor family (Biaggioni and Robertson, 2018).

Potassium channels including ATP-sensitive potassium $\left(\mathrm{K}_{\mathrm{ATP}}\right)$ channels play an important role in the vascular tonus due to their effects on membrane potential. The opening of $\mathrm{K}_{\mathrm{ATP}}$ channels results in membrane hyperpolarization in smooth muscle and hence contributes to vasorelaxation (Sobey, 2001). Recently, $K_{\text {ATP }}$ channels are reported to be also present in the vascular endothelium and have a functional role in the vascular reactivity (Aziz et al., 2017). The vasodilatory action of adenosine through its receptors has also been shown to be associated with activation of endothelial $\mathrm{K}_{\mathrm{ATP}}$ channels (Kuo and Chancellor, 1995). Adenosine receptors are also coupled with stimulatory G-protein like $\beta_{2^{-}}$and $\beta_{3^{-}}$ ARs (Biaggioni and Robertson, 2018).

Most studies investigating vascular action of nebivolol have mainly focused on adrenergic receptors linking with NO production to explain the mechanism of vasorelaxation. Experimental evidence regarding the role $\mathrm{K}_{\mathrm{ATP}}$ channels in the vasoleraxant effect of nebivolol is still limited. Therefore, it would be informative to investigate the role of $\mathrm{K}_{\mathrm{ATP}}$ channels in the vasorelaxant effect of nebivolol. This study was aimed to investigate whether $\mathrm{K}_{\text {ATP }}$ channels could involve in the vasorelaxant response to nebivolol in the endothelium-intact aorta isolated from rat.

\section{Methods}

\section{Drugs and chemicals}

Nebivolol hydrochloride, phenylephrine hydrochloride (PE), acetylcholine hydrochloride (ACh) and N $\omega$-Nitro-L-arginine methyl ester hydrochloride (L-NAME) were obtained from Sigma-Aldrich. In addition, glibenclamide was obtained from Tocris. Nebivolol and glibenclamide was dissolved in dimethylsulphoxide as described previously (Rautureau et al., 2002; Pullen et al., 2014) and the final concentration of the solvent in the organ bath was less than $0.01 \%(\mathrm{v} / \mathrm{v})$.

\section{Animals}

Experimental protocols were approved by Ethical Committee for Experimental Research on Animals. Male Sprague-Dawley rats (250-300g) were used in this study. The rats were housed in cages under 12/12 hours light/dark cycle and were allowed ad libitum access to standard laboratory diet and tap water.

\section{Preparation of Rat Thoracic Aortic Rings}

The anesthetized rats were sacrificed by cervical dislocation and the descending thoracic aorta was rapidly dissected out and placed in Krebs-Henseleit solution (KHS) composed of (mM): $\mathrm{NaCl}, 118 ; \mathrm{KCl}$, 4.7; $\mathrm{MgSO} 4 \cdot 7 \mathrm{H} 2 \mathrm{O}, 1.2 ; \mathrm{KH} 2 \mathrm{PO} 4,1.2 ; \mathrm{CaCl} 2,2.5$; NaHCO3, 25; and glucose, 11). The thorasic aorta was carefully cleaned of surrounding fat and connective tissue and cut into aortic rings approximately $3 \mathrm{~mm}$ in length. The aortic rings were mounted between two stainless hooks in $10 \mathrm{ml}$ organ baths containing KHS (at $37 \circ \mathrm{C}$ bubbled with $95 \%$ O2 $+5 \% \mathrm{CO} 2$ ) and attached to force displacement that were connected to a computer for isometric force recording.

\section{Experimental protocol}

The aortic ring was held at a resting tension of $2 \mathrm{~g}$ and allowed to equilibrate for $1 \mathrm{~h}$ with washing fresh KHS every $15 \mathrm{~min}$. After this equilibration period, the integrity of the vascular endothelium was checked by contracting the tissues with PE $(1 \mu \mathrm{M})$ and adding $\mathrm{ACh}(10 \mu \mathrm{M})$. Only tissues that relaxed by more than $50 \%$ to ACh were included in this study.

In order to elucidate the impact of KATP channels in the nebivolol-mediated vasorelaxation, some aortic rings were incubated with the glibenclamide (KATP channel blocker, $10 \mu \mathrm{M}, \mathrm{n}=6$ ) for 30 minutes. Additionally, the NO-dependent effect of nebivolol was also evaluated by the incubation of some aortic rings with L-NAME (endothelial nitric oxide synthase inhibitor, $100 \mu \mathrm{M}, \mathrm{n}=4$ ) for 20 minutes. Other aortic rings were not incubated and served as controls $(n=5)$. Nebivolol (10-10-10-4 M) was cumulatively added to organ bath to obtain cumulative concentration-relaxation curves (CCRCs) in the aortic rings precontracted with potassium chloride $(\mathrm{KCl}, 30 \mathrm{mM})$. The concentrations of antagonists were selected based on preliminary experiments and previous studies (Sobey, 2001; Aziz et al., 2017). 


\section{Statistical analysis}

Data are expressed as mean \pm SEM. Relaxation is expressed as the percentage of the contraction caused by $\mathrm{KCl}$. The analysis was performed using the statistical software package (Graphpad Prism, USA). Statistical significance was tested by ANOVA followed by the Bonferroni Comparison post-test. Efficacy of nebivolol was expressed as maximum relaxation $\left(\mathrm{E}_{\max }\right)$ and determined as a percentage of the $\mathrm{KCl}$ precontraction. $\mathrm{pD}_{2}$ (negative logarithm of the half maximum effective concentration (EC50)) values were calculated for potency of nebivolol. Differences were considered to be statistically significant when $\mathrm{p}<0.05$.

\section{Results}

Nebivolol produced concentration-dependent relaxation in the rat aorta precontracted with $\mathrm{KCl}$ (Fig $1, n=5)$. The vasorelaxant effect of nebivolol was significantly inhibited after incubation of aortic rings with glibenclamide $(10 \mu \mathrm{M}, \mathrm{n}=6)$ or L-NAME $(100$ $\mu \mathrm{M}, \mathrm{n}=4$ ). (Fig $1, * \mathrm{p}<0.05$ ). Additionally, as shown in Figure 1, incubation of aortic rings with glibenclamide $(10 \mu \mathrm{M})$ or L-NAME $(100 \mu \mathrm{M})$ caused a rightward shift of the CCRCs.

The Emax values for nebivolol were not significantly different in the aortic rings incubated with glibenclamide $(10 \mu \mathrm{M}, \mathrm{n}=6)$ or L-NAME $(100$ $\mu \mathrm{M}, \mathrm{n}=4)$ compared to controls $(\mathrm{n}=5)($ Fig $2, \mathrm{p}>0.05)$.

The potency of nebivolol as attested by pD2 values were reduced by the presence of glibenclamide $(10 \mu \mathrm{M}, \mathrm{n}=6)$ or L-NAME $(100 \mu \mathrm{M}, \mathrm{n}=4)$ (Fig 3).

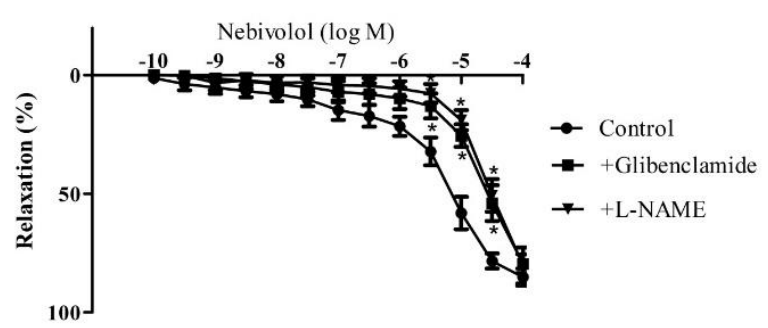

Figure 1. Percentage relaxations of endothelium-intact aortic rings in response to cumulative concentrations of nebivolol in the absence $(n=5)$ or presence of glibenclamide $(10 \mu \mathrm{M}, \mathrm{n}=6)$ or L-NAME $(100 \mu \mathrm{M}, \mathrm{n}=4)$. $* \mathrm{p}<0.05$ vs Control.

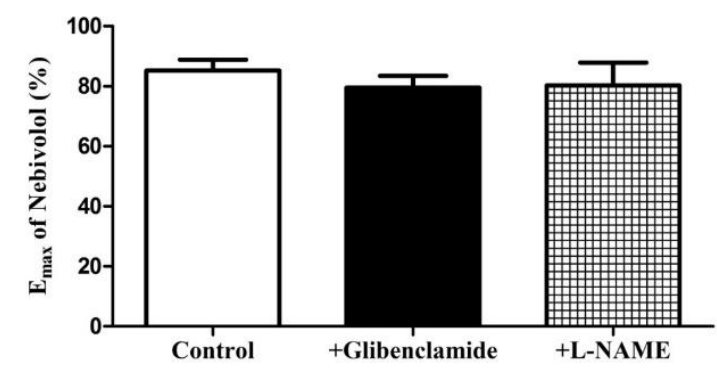

Figure 2. $E_{\max }$ of nebivolol in the the absence $(n=5)$ or presence of glibenclamide $(10 \mu \mathrm{M}, \mathrm{n}=6)$ or L-NAME (100 $\mu \mathrm{M}, \mathrm{n}=4)$ in the endothelium-intact aortas.

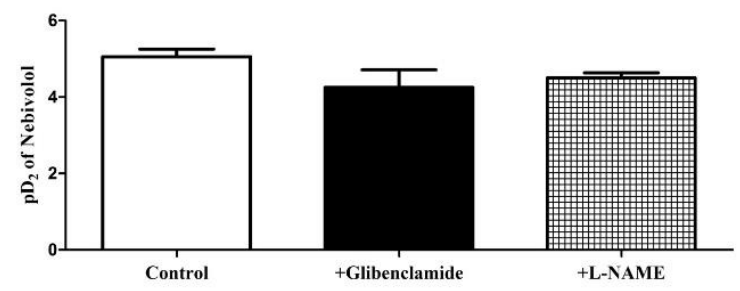

Figure 3. $\mathrm{pD}_{2}$ of nebivolol in the the absence $(\mathrm{n}=5)$ or presence of glibenclamide $(10 \mu \mathrm{M}, \mathrm{n}=6)$ or L-NAME (100 $\mu \mathrm{M}, \mathrm{n}=4)$ in the endothelium-intact aortas.

\section{Discussion}

In the present study, nebivolol produced NOdependent vasorelaxation in the endothelium-intact aorta precontracted with $\mathrm{KCl}$. In addition, the present findings provide a new mechanism showing the involvement of $\mathrm{K}_{\mathrm{ATP}}$ channels in the vasorelaxant response to nebivolol in the endothelium-intact aorta.

$\mathrm{K}_{\mathrm{ATP}}$ channels play an important regulator role in the vascular tonus by their ability to couple cellular metabolism with membrane potential (Aziz et al., 2017). In this regard, membrane hyperpolarization induced by activation of sarcolemmal vascular smooth muscle $\mathrm{K}_{\mathrm{ATP}}$ channels ( $\operatorname{sarcK}_{\mathrm{ATP}}$ channels) results in the vasorelaxant response (Sobey, 2001). Therefore, most in vitro experiments were focused to clarify that the role of sarcK $_{\text {ATP }}$ channels in the vasorelaxant response using the endotheliumdenuded aortic preparations (Pantan et al., 2014; Arsyad and Dobson, 2016). However, endothelial $\mathrm{K}_{\text {ATP }}$ channels also exist (Aziz et al., 2017) and the vasorelaxant effect may be evaluated in the presence of both endothelial $\mathrm{K}_{\mathrm{ATP}}$ and sarcK $\mathrm{K}_{\mathrm{ATP}}$ channels to obtain whole vascular response. Although the functional role of sarcK $\mathrm{K}_{\mathrm{ATP}}$ channels is well known, there is limited information regarding the involvement of endothelial $\mathrm{K}_{\mathrm{ATP}}$ channels in vascular function. Indeed, it has been reported that $\mathrm{K}_{\mathrm{ATP}}$ channels are also present in the vascular endothelium 
and contribute to the vascular reactivity in the coronary arteries (Aziz et al., 2017). Structurally, $\mathrm{K}_{\text {ATP }}$ channels consist of subunits including poreforming inward rectifier Kir6.x subunits (Kir6.1 or Kir6.2) and regulatory sulfonylurea receptors (SUR1, SUR2A, or SUR2B) (Tinker et al., 2014). The different combinations of these subunits form KATP channels which have distinct pharmacological and electrophysiological properties as in vascular and pancreatic beta cells (Aziz et al., 2015; Ashcroft et al., 2017). Aziz et al. found that Kir6.1 subtype is the relevant subunit in the endothelial KATP channels similar to sarcKATP channels (Aziz et al., 2017). Moreover, endothelial KATP channels are also found to be partly involved in the vasodilatory action of adenosine (Kuo and Chancellor, 1995). This seems to be associated with direct phosphorylation of these channels via protein kinase A which is activated by stimulation of G-protein coupled adenosine receptors by adenosine (Aziz et al., 2017). The activation is also pronounced through distinct stimulatory G-protein coupled receptors such as $\beta$-adrenergic receptors $(\beta$ ARs) and this mechanism is involved in $\beta$-ARmediated vasorelaxant response (Biaggioni and Robertson, 2018). Nebivolol produces an endothelium-dependent vasorelaxant effect primarily attributed to endothelial $\beta 2$ - and/or $\beta 3$-ARs stimulation and subsequent activation of eNOS (Broeders et al., 2000; de Groot et al., 2003). NO is an endothelium-derived relaxing factor which increases the production of cyclic guanosine monophosphate (cGMP) by activating of soluble guanylate cyclase in the vascular smooth muscle (Vanhoutte et al., 2017). Alternatively, NO could also induce hyperpolarization in the smooth muscle of different arteries, including the rat aorta (Vanheel et al., 1994).

A critical question is whether $\mathrm{K}_{\mathrm{ATP}}$ channels play any role in the nebivolol-induced relaxation due to their effects on membrane potential in the aorta precontracted by $\mathrm{KCl}$-mediated membrane depolarization. The vasorelaxant activity of nebivolol seems to be primarily based on increased endothelial NO production by stimulation of endothelial $\beta_{2}-$ and/or $\beta_{3}$-ARs, as mentioned before. However, the NO production induced by nebivolol may also be under the modulation of endothelial $\mathrm{K}_{\mathrm{ATP}}$ channels. This hypothesis is supported by the findings of present study showing a similar inhibition of nebivolol-induced vasorelaxant response in the presence of $\mathrm{K}_{\mathrm{ATP}}$ channel blocker or endothelial nitric oxide synthase inhibitor. This outcome is also supported by another study which shows that NOinduced changes in membrane potential were inhibited by $\mathrm{K}_{\text {ATP }}$ channel blocker (Garland and McPherson, 1992). Unfortunately, a limitation of the present study was the lack of measurement of membrane potentials due to the insufficiency of technical resources at the laboratory.

In previous organ bath experiments, nebivolol has been similarly found to induce relaxation in the rat aorta precontracted with $\mathrm{KCl}$ (de Groot et al., 2003; Wang et al., 2009). Additionally, they have also shown that this effect is NO-dependent because it could be abrogated by endothelial NO synthase inhibitor (de Groot et al., 2003; Wang et al., 2009). However, Wang et al. (2009) found that glibenclamide failed to inhibit nebivolol-induced relaxation in the rat aorta. This discrepancy may be explained by concentrations of glibenclamide and $\mathrm{KCl}$ that differ from the present study. Because, the appropriate concentrations of glibenclamide and $\mathrm{KCl}$ were selected based on a preliminary experiments of the present study. For example, the concentration of $\mathrm{KCl}(30 \mathrm{mM})$ was tested and selected because it has been found that nebivolol was failed to induce relaxation when higher concentration $(60 \mathrm{mM})$ of $\mathrm{KCl}$ was used in the experimental protocol (data not shown). In addition to this, the concentrations of glibenclamide and $\mathrm{KCl}$ used in the present study were in line with previous in vitro studies in the rat aorta (Ito et al., 1997; Erdei et al., 2006; Mateus et al., 2019).

\section{Conclusion}

In conclusion, the present findings suggest for the first time that activation of $\mathrm{K}_{\mathrm{ATP}}$ channels is involved in the relaxant response to nebivolol in the rat aorta precontracted with $\mathrm{KCl}$. The vasorelaxant effect of nebivolol is also found to be NO-dependent. Taken together, possible mechanisms by which $\mathrm{NO}$ and $\mathrm{K}_{\text {ATP }}$ channels could involve in the nebivol-induced relaxation in the endothelium-intact aortas were summarized in the Fig 4. However, further studies are needed to clarify the signalling pathways including endothelial and sarcolemmal $\mathrm{K}_{\mathrm{ATP}}$ channels in the nebivolol-induced vasorelaxation. 


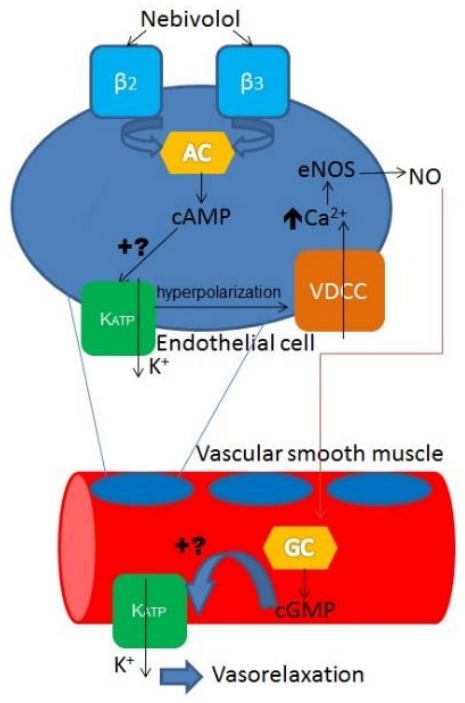

Fig 4. Possible mechanisms leading to nebivolol-induced relaxation in the endothelium-intact aorta.

\section{Acknowledgements}

I would like to thank to Zeynep Elif Yeşilyurt (PhD student at Ankara University Faculty of Pharmacy Department of Pharmacology) for technical support.

Ethics Committee Approval: Kobay Experimental Animal Laboratory Local Ethical Committee, Approval date and number: 14.01.2020/451.

Peer-review: Externally peer-reviewed.

Author Contributions: Concept HOAC; Design HOAC; Supervision HOAC; Materials HOAC; Data collection and/or Processing HOAC; Analysis and/or Interpretation HOAC; Literature Review HOAC; Writing HOAC; Critical Review HOAC.

Conflict of Interest: No conflict of interest was declared by the author.

Financial Disclosure: The author declared that this study hasn't received no financial support.

\section{References}

Arsyad A, Dobson GP. Lidocaine relaxation in isolated rat aortic rings is enhanced by endothelial removal: possible role of $\mathrm{Kv}$, KATP channels and A2a receptor crosstalk. BMC Anesthesiol 2016; 16(1): 121.

Ashcroft FM, Puljung MC, Vedovato N. Neonatal Diabetes and the KATP Channel: From Mutation to Therapy. Trends Endocrinol Metab 2017; 28 (5): 377-387.

Aziz Q, Li Y, Tinker A. ATP-sensitive potassium channels and vascular function. Channels (Austin) 2015; 9(1): 3-4.
Aziz Q, Li Y, Anderson N, Ojake L, Tsisanova E, Tinker A. Molecular and functional characterization of the endothelial ATP-sensitive potassium channel. J Biol Chem 2017; 292(43): 17587-17597.

Biaggioni I, Robertson D. Adrenoceptor Agonists \& Sympathomimetic Drugs. Katzung, B.G. (ed). Basic \& Clinical Pharmacology. USA: McGrawHill Education; 2018, p:137-155.

Broeders MA, Doevendans PA, Bekkers BC, Bronsaer R, van Gorsel E, Heemskerk JW, et al. Nebivolol: a third-generation beta-blocker that augments vascular nitric oxide release: endothelial beta (2)-adrenergic receptor-mediated nitric oxide production. Circulation 2000; 102(6): 677-684.

Cicero AFG, Kuwabara M, Borghi C. A Critical Review of Nebivolol and its Fixed-Dose Combinations in the Treatment of Hypertension. Drugs 2018; 78(17): 1783-1790.

de Groot AA, Mathy MJ, van Zwieten PA, Peters SL. Involvement of the beta3 adrenoceptor in nebivolol-induced vasorelaxation in the rat aorta. J Cardiovasc Pharmacol 2003; 42(2): 232-236.

Erdei N, Papp Z, Pollesello P, Edes I, Bagi Z. The levosimendan metabolite OR-1896 elicits vasodilation by activating the $\mathrm{K}(\mathrm{ATP})$ and $\mathrm{BK}(\mathrm{Ca})$ channels in rat isolated arterioles. $\mathrm{Br} \mathrm{J}$ Pharmacol 2006; 148(5): 696-702.

Félétou M, Vanhoutte PM. Endothelial dysfunction: a multifaceted disorder. Am J Physiol Heart Circ Physiol 2006; 91(3): H985-1002

Garland CJ, McPherson GA. Evidence that nitric oxide does not mediate the hyperpolarization and relaxation to acetylcholine in the rat small mesenteric artery. Br J Pharmacol 1992; 105(2): 429-435.

Ito M, Yamamoto I, Naruse A, Suzuki Y, Satake N, Shibata S. Impaired relaxing response to isoprenaline in isolated thoracic aorta of nephrotic rats: decrease in release of EDRF from endothelial cells. J Cardiovasc Pharmacol 1997; 29(2): 232239.

Kuo L, Chancellor JD. Adenosine potentiates flowinduced dilation of coronary arterioles by activating KATP channels in endothelium. Am J Physiol 1995; 269: H541-H549.

Mateus LS, Albuquerque AAS, Celotto AC, Evora PRB. In vitro evidence that endotheliumdependent vasodilatation induced by clozapine is mediated by an ATP-sensitive potassium channel. Pharmacol Rep 2019; 71(3): 522-527. 
Olawi N, Krüger M, Grimm D, Infanger M, Wehland M. Nebivolol in the treatment of arterial hypertension. Basic Clin Pharmacol Toxicol 2019; 125(3): 189-201.

Pantan R, Onsa-Ard A, Tocharus J, Wonganan O, Suksamrarn A, Tocharus C. Endotheliumindependent vasorelaxation effects of 16-Oacetyldihydroisosteviol on isolated rat thoracic aorta. Life Sci 2014; 116(1):31-36.

Pullen C, Coulson FR, Fenning A. Effects of Resveratrol and Nebivolol on Isolated Vascular and Cardiac Tissues from Young Rats. Adv Pharmacol Sci 2014; 2014: 720386.

Rautureau Y, Toumaniantz G, Serpillon S, Jourdon P, Trochu JN, Gauthier C. Beta 3-adrenoceptor in Rat Aorta: Molecular and Biochemical Characterization and Signalling Pathway. $\mathrm{Br} \mathrm{J}$ Pharmacol 2002; 137(2):153-61.

Sobey CG. Potassium channel function in vascular disease. Arterioscler Thromb Vasc Biol 2001; 21(1): 28-38

Tinker A, Aziz Q, Thomas A. The role of ATPsensitive potassium channels in cellular function and protection in the cardiovascular system. $\mathrm{Br} \mathbf{J}$ Pharmacol 2014; 171(1): 12-23.

Vanheel B, Van de Voorde J, Leusen I. Contribution of nitric oxide to the endothelium-dependent hyperpolarization in rat aorta. J Physiol. 1994; 475(2): 277-284.

Vanhoutte PM, Shimokawa H, Feletou M, Tang EH. Endothelial dysfunction and vascular disease - a 30th anniversary update. Acta Physiol (Oxf). 2017; 219(1): 22-96.

Wang Y, Zhang M, Liu Y, Li J, Song E, Niu L, Cheng N. Neither K+ channels nor PI3K/Akt mediates the vasodilative effect of nebivolol on different types of rat arteries. J Cardiovasc Pharmacol Ther 2009; 14(4): 332-338. 